\title{
Bronchodilator reversibility as a diagnostic test for adult asthma: findings from the population-based Tasmanian Longitudinal Health Study
}

Daniel J. Tan ${ }^{1}$, Caroline J. Lodge ${ }^{1}$, Adrian J. Lowe ${ }^{1}$, Dinh S. Bui ${ }^{1}$, Gayan Bowatte ${ }^{1,2,3}$ David P. Johns ${ }^{4}$, Garun S. Hamilton ${ }^{5,6}$, Paul S. Thomas ${ }^{7}$, Michael J. Abramson $\mathbb{1}^{8}$, E. Haydn Walters ${ }^{4}$, Jennifer L. Perret (10) $1,9,10$ and Shyamali C. Dharmage ${ }^{1,10}$

Affiliations: ${ }^{1}$ Allergy and Lung Health Unit, Centre for Epidemiology and Biostatistics, School of Population and Global Health, University of Melbourne, Melbourne, Victoria, Australia. ${ }^{2}$ Dept of Basic Sciences, Faculty of Allied Health Sciences, University of Peradeniya, Peradeniya, Sri Lanka. ${ }^{3}$ National Institute of Fundamental Studies, Kandy, Sri Lanka. ${ }^{4}$ School of Medicine, University of Tasmania, Hobart, Tasmania, Australia. ${ }^{5}$ Monash Lung and Sleep, Monash Health, Clayton, Victoria, Australia. 'School of Clinical Sciences, Monash University, Clayton, Victoria, Australia. ${ }^{7}$ Prince of Wales' Clinical School, Faculty of Medicine, University of New South Wales, Sydney, Australia. ${ }^{8}$ School of Public Health \& Preventive Medicine, Monash University, Melbourne, Victoria, Australia. ${ }^{9}$ Institute for Breathing and Sleep, Melbourne, Victoria, Australia. ${ }^{10}$ These authors contributed equally.

Correspondence: Shyamali Dharmage, Level 3, 207 Bouverie Street, Parkville 3052, VIC, Australia. E-mail: s.dharmagedunimelb.edu.au

ABSTRACT Bronchodilator reversibility (BDR) is often used as a diagnostic test for adult asthma. However, there has been limited assessment of its diagnostic utility. We aimed to determine the discriminatory accuracy of common BDR cut-offs in the context of current asthma and asthma-COPD overlap (ACO) in a middle-aged community sample.

The Tasmanian Longitudinal Health Study is a population-based cohort first studied in 1968 ( $\mathrm{n}=8583)$. In 2012, participants completed respiratory questionnaires and spirometry ( $n=3609$; mean age 53 years). Receiver operating characteristic (ROC) curves were fitted for current asthma and ACO using continuous BDR measurements. Diagnostic parameters were calculated for different categorical cut-offs.

Area under the ROC curve (AUC) was highest when BDR was expressed as change in forced expiratory volume in $1 \mathrm{~s}\left(\mathrm{FEV}_{1}\right)$ as a percentage of initial $\mathrm{FEV}_{1}$, as compared with predicted $\mathrm{FEV}_{1}$. The corresponding AUC was 59\% (95\% CI 54-64\%) for current asthma and 87\% (95\% CI 81-93\%) for ACO. Of the categorical cut-offs examined, the European Respiratory Society/American Thoracic Society threshold $(\geqslant 12 \%$ from baseline and $\geqslant 200 \mathrm{~mL}$ ) was assessed as providing the best balance between positive and negative likelihood ratios (LR+ and LR-, respectively), with corresponding sensitivities and specificities of $9 \%$ and $97 \%$, respectively, for current asthma (LR+ 3.26, LR- 0.93), and 47\% and 97\%, respectively, for ACO (LR+ 16.05, LR- 0.55).

With a threshold of $\geqslant 12 \%$ and $\geqslant 200 \mathrm{~mL}$ from baseline, a positive BDR test provided a clinically meaningful change in the post-test probability of disease, whereas a negative test did not. BDR was more useful as a diagnostic test in those with co-existent post-bronchodilator airflow obstruction (ACO).

@ERSpublications

Using the commonly adopted threshold, a positive BDR test provides a meaningful change in post-test probability of adult asthma, whereas a negative test does not. Discriminatory accuracy is much greater in those with coexistent post-BD airflow obstruction. https://bit.ly/3gPvlm8

Cite this article as: Tan DJ, Lodge CJ, Lowe AJ, et al. Bronchodilator reversibility as a diagnostic test for adult asthma: findings from the population-based Tasmanian Longitudinal Health Study. ERJ Open Res 2021; 7: 00042-2020 [https://doi.org/10.1183/23120541.00042-2020].

This article has supplementary material available from openres.ersjournals.com

Received: 27 Jan 2020 | Accepted after revision: 9 Dec 2020

Copyright $\odot$ ERS 2021. This article is open access and distributed under the terms of the Creative Commons Attribution Non-Commercial Licence 4.0. 


\section{Introduction}

Asthma is a chronic inflammatory airways disease characterised by variable expiratory airflow limitation and respiratory symptoms which vary over time and in intensity [1]. A diagnosis of asthma is usually suspected based on clinical features, and tests of expiratory airflow are then used to confirm the diagnosis [1]. To avoid misdiagnosis and inappropriate treatment, international guidelines recommend a "test before treat" approach wherever possible. In more symptomatic individuals for whom early treatment is clinically indicated, spirometry is recommended within the first 1-3 months of treatment [1-3].

Of the available diagnostic tests for asthma, the Global Initiative for Asthma recommends spirometry to assess bronchodilator reversibility (BDR) as the first-line investigation [1]. BDR measures the increase in expiratory airflow in response to an inhaled short-acting bronchodilator and is usually based on the change in the forced expiratory volume in $1 \mathrm{~s}\left(\Delta \mathrm{FEV}_{1}\right)$ [4]. "Significant reversibility" of $\mathrm{FEV}_{1}$ and/or the forced vital capacity (FVC) is considered a hallmark of current asthma and "rules in", i.e. confirms, the diagnosis in most algorithms $[1,2]$. However, it is estimated that $\sim 80 \%$ of those with current asthma do not exhibit significant reversibility $[5,6]$, and a negative BDR test typically warrants further investigations. Other recommended tests include nonspecific bronchial provocation or exercise challenge tests [1]. In addition, variable airflow limitation can be demonstrated over time or in response to controller treatment (e.g. inhaled corticosteroids (ICS)) to give a positive diagnosis [1].

Although BDR testing is commonly used, its clinical usefulness is still debated. A recent review of the historical development of recommendations for BDR testing has identified several important knowledge gaps [7]. These include a lack of consensus on which spirometric parameters BDR should be defined by and what constituted a significant response; insufficient data on sensitivities and specificities of common BDR cut-offs; and limited normative data derived from healthy general populations [7]. The latter point has more recently been addressed in an analysis of worldwide data from the Burden of Obstructive Lung Disease study and a pooled analysis of three large European population-based cohorts $[6,8]$ in which the prevalence of a significant response in healthy adults (defined as an increase in $\mathrm{FEV}_{1}$ of $\geqslant 12 \%$ from baseline) was reported to be $5.9 \%$ and $4.4 \%$, respectively. Additionally, both studies provided data on BDR in different obstructive airways diseases, but defined current asthma based on symptoms and/or healthcare utilisation over the past 12 months. This definition, while common in epidemiological studies, may not be appropriate given the variable nature of asthma over time.

Current international guidelines recommend a cut-off for the diagnosis of asthma of $\triangle \mathrm{FEV}_{1} \geqslant 12 \%$ from baseline and $\geqslant 200 \mathrm{~mL}[9,10]$. In some cases, higher thresholds such as $\Delta \mathrm{FEV}_{1} \geqslant 15 \%$ from baseline and $\geqslant 400 \mathrm{~mL}$ are also used $[9,10]$. However, there are still limited data on the diagnostic parameters (sensitivity and specificity) of these thresholds. While lower cut-offs such as $\Delta \mathrm{FEV}_{1} \geqslant 9 \%$ or $\geqslant 10 \%$ from baseline have been proposed and studied previously [11], they have not been widely adopted due to impractically high false-positive rates. Moreover, there is limited evidence on whether these thresholds are more useful in certain subgroups of asthma, such as those with asthma-COPD overlap, in whom the prevalence of BDR has been shown to be much higher [2].

In this study, we aimed to contribute additional normative data on BDR from an Australian population-based cohort and to examine the discriminatory accuracy of BDR for adult asthma, with and without fixed airflow obstruction. We examined the diagnostic parameters of different BDR measurements and cut-offs in both general and symptomatic samples.

\section{Methods \\ Tasmanian Longitudinal Health Study}

Methods of the baseline study and subsequent follow-ups have been described elsewhere [12, 13]. In brief, the Tasmanian Longitudinal Health Study (TAHS) is a population-based cohort of children born in 1961 and attending school in Tasmania, Australia in 1968 ( $\mathrm{n}=8583)$. Large-scale follow-ups were conducted in $1974(n=7380)$ and $2002(n=5729)$. Between 2012 and 2016, when participants were aged 53 years, the cohort was traced and participants completed respiratory questionnaires $(n=3609)$. Of these, $2646(73 \%)$ opted to participate in a clinical study and spirometry. The current analysis includes participants in the 2012 follow-up.

\section{Data collection}

Spirometry was performed according to the joint American Thoracic Society (ATS)/European Respiratory Society (ERS) guidelines [14]. Lung function was assessed before and $15 \mathrm{~min}$ after inhalation of $300 \mu \mathrm{g}$ salbutamol administered via a spacer. Predicted values for spirometry were derived from reference equations published by the Global Lung Initiative [15]. 


\section{Definitions}

Current doctor-diagnosed asthma (“current asthma”) was defined as asthma-related symptoms, healthcare or medication utilisation in the past 1 month in participants who reported doctor-diagnosed asthma and did not have post-bronchodilator (BD) airflow obstruction. Post-BD airflow obstruction consistent with COPD ("COPD") was defined as post-BD $\mathrm{FEV}_{1} / \mathrm{FVC}$ ratio below the lower limit of normal. "Asthma-COPD overlap" (ACO) was defined by the combined criteria of current doctor-diagnosed asthma and post-BD airflow obstruction. The three disease categories were mutually exclusive.

Participants not meeting the criteria for current asthma, COPD or ACO were defined as having no airways disease. Of those without airways diseases, a reference sample of healthy adults was delineated using the following criteria: 1) never-asthma based on prospective data collected in 1968, 1974 and 2004; 2) never-smokers; and 3) no respiratory symptoms in the past 12 months (wheeze, shortness of breath or chest tightness). Normative data (i.e. mean $\pm \mathrm{SD}$ and upper limits of normal of BDR) were obtained from this reference sample.

\section{BDR measurements and cut-offs}

Three continuous BDR measurements were examined: 1) absolute volume change in $\mathrm{FEV}_{1}$ in $\mathrm{mL}\left(\Delta \mathrm{FEV}_{1}\right)$; 2) $\Delta \mathrm{FEV}_{1}$ as a percentage of the initial $\mathrm{FEV}_{1}\left(\triangle \mathrm{FEV}_{1}\right.$ initial), and (3) $\Delta \mathrm{FEV}_{1}$ as a percentage of the predicted $\mathrm{FEV}_{1}\left(\Delta \mathrm{FEV}_{1}\right.$ pred) [7].

a)

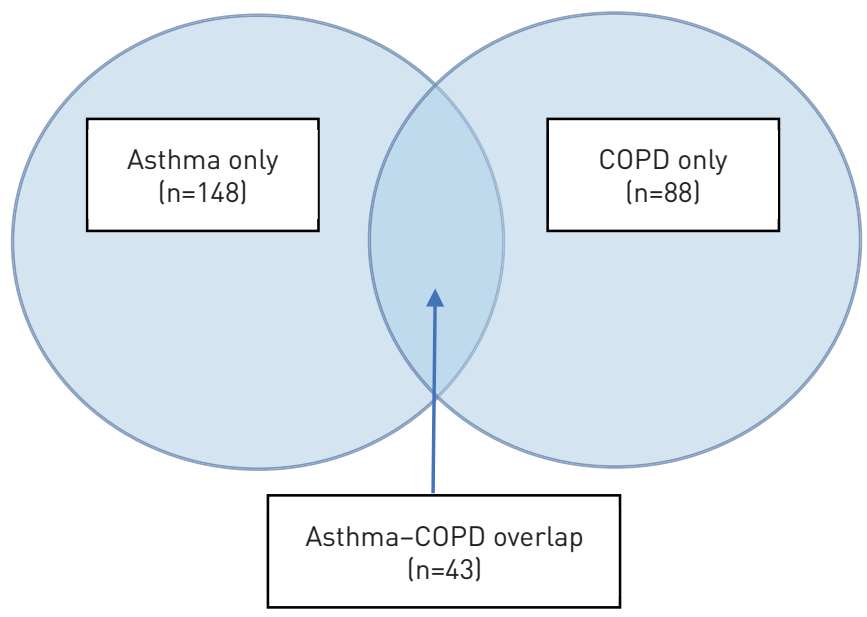

b)

Symptomatic sampleी $(n=886)$

No airways disease $(n=661)$

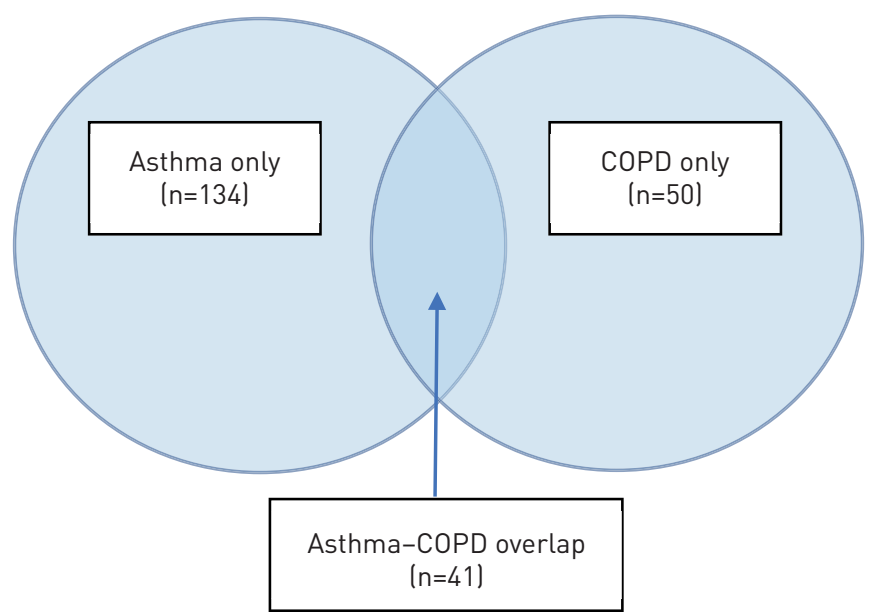

FIGURE 1 Sample sizes of the disease subgroups in the al general and b) symptomatic samples. ${ }^{\#}$ : never-asthma, never-smoker, no respiratory symptoms in the past 12 months; ๆ: limited to participants who responded positively to one of five survey questions related to wheeze, shortness of breath or chest tightness in the past 12 months. 
Two cut-offs recommended by ATS/ERS were examined: 1) $\Delta \mathrm{FEV}_{1} \geqslant 12 \%$ from baseline and $\geqslant 200 \mathrm{~mL}$; and 2) $\Delta \mathrm{FEV}_{1} \geqslant 15 \%$ from baseline and $\geqslant 400 \mathrm{~mL}[1,16]$. These cut-offs were compared to cut-offs based on the reference sample upper limits of normal (ULN; 95th percentile) of the three continuous BDR measurements.

\section{Statistical analysis}

Receiver operating characteristic (ROC) curves were fitted for current asthma and ACO using the three continuous $\mathrm{BDR}$ measurements $\left(\Delta \mathrm{FEV}_{1}, \Delta \mathrm{FEV}_{1}\right.$ initial and $\Delta \mathrm{FEV}_{1}$ pred) as diagnostic classifiers against participants with no airways disease. When analyses were performed for current asthma, ACO participants were excluded, and vice versa.

For each categorical cut-off, the following diagnostic parameters were calculated: sensitivity, specificity, positive predictive value, negative predictive value, positive likelihood ratio, negative likelihood ratio and diagnostic odds ratio. The diagnostic odds ratio is a single indicator of diagnostic test performance calculated as the ratio between the positive and negative likelihood ratios [17]. Two statistical cut-offs, the Youden and Liu indexes, were examined for reference; methods for this approach are presented in supplementary methods E1.

All analyses were first conducted in the general population sample (whole TAHS cohort) to evaluate the discriminatory accuracy of BDR in nonselected settings (figure 1). Analyses were then repeated in the

\begin{tabular}{|c|c|c|c|c|c|}
\hline & \multicolumn{2}{|c|}{ No airways disease $(n=2367)^{\#}$} & \multirow[t]{2}{*}{ Asthma } & \multirow[t]{2}{*}{ COPD } & \multirow[t]{2}{*}{ ACO } \\
\hline & $\begin{array}{l}\text { Reference } \\
\text { sample }\end{array}$ & Others & & & \\
\hline Participants & 552 & 1815 & 148 & 88 & 43 \\
\hline Age years & $52.5 \pm 0.8$ & $52.7 \pm 0.8$ & $52.9 \pm 0.8$ & $52.8 \pm 0.7$ & $52.8 \pm 0.8$ \\
\hline BMI $\mathrm{kg} \cdot \mathrm{m}^{-2}$ & $27.7 \pm 5.1$ & $28.8 \pm 5.4$ & $30.3 \pm 6.7$ & $27.1 \pm 5.8$ & $28.8 \pm 7.2$ \\
\hline Female & $285(52)$ & 937 (52) & 77 (52) & $43(49)$ & $19(44)$ \\
\hline \multicolumn{6}{|l|}{ Smoking history } \\
\hline Never & $549(100)$ & $567(32)$ & 77 (53) & $15(17)$ & 8 (19) \\
\hline Former & & 909 (51) & $56(38)$ & $24(28)$ & $17(40)$ \\
\hline Current & & 324 (18) & $13(9)$ & $48(55)$ & $18(42)$ \\
\hline \multicolumn{6}{|l|}{ Asthma history } \\
\hline Early-onset & & & $75(51)$ & & $19(44)$ \\
\hline Current ICS use & & & $76(51)$ & $1(1)$ & $18(42)$ \\
\hline \multicolumn{6}{|l|}{ Asthma severity } \\
\hline Intermittent & & & $17(13)$ & & $1(4)$ \\
\hline Mild persistent & & & $33(25)$ & & $8(29)$ \\
\hline $\begin{array}{l}\text { Moderate-severe } \\
\text { persistent }\end{array}$ & & & $82(62)$ & & $19(68)$ \\
\hline \multicolumn{6}{|l|}{ Pre-BD spirometry } \\
\hline $\mathrm{FEV}_{1} \%$ pred & $102.0 \pm 11.8$ & $98.7 \pm 13.2$ & $91.6 \pm 15.1$ & $78.5 \pm 15.1$ & $64.7 \pm 18.8$ \\
\hline FVC \% pred & $102.5 \pm 11.8$ & $100.6 \pm 12.4$ & $96.7 \pm 14.5$ & $99.6 \pm 15.3$ & $90.0 \pm 18.7$ \\
\hline $\mathrm{FEV}_{1} / \mathrm{FVC} \%$ pred & $99.2 \pm 6.1$ & $97.9 \pm 6.5$ & $94.5 \pm 7.4$ & $78.3 \pm 8.4$ & $70.7 \pm 11.5$ \\
\hline \multicolumn{6}{|l|}{ Post-BD spirometry } \\
\hline $\mathrm{FEV}_{1} \%$ pred & $104.8 \pm 11.8$ & $101.9 \pm 12.8$ & $96.0 \pm 13.8$ & $82.5 \pm 14.3$ & $72.4 \pm 19.0$ \\
\hline FVC \% pred & $102.3 \pm 11.7$ & $100.8 \pm 12.1$ & $98.1 \pm 13.4$ & $102.8 \pm 14.9$ & $96.7 \pm 17.5$ \\
\hline $\mathrm{FEV}_{1} / \mathrm{FVC} \%$ pred & $102.2 \pm 5.2$ & $100.8 \pm 6.0$ & $97.8 \pm 6.4$ & $79.8 \pm 7.0$ & $73.8 \pm 11.6$ \\
\hline \multicolumn{6}{|l|}{ BDR indices } \\
\hline$\Delta \mathrm{FEV}_{1} \mathrm{~mL}$ & $91.9 \pm 121.0$ & $102.1 \pm 132.2$ & $145.7 \pm 159.3$ & $127.5 \pm 199.2$ & $257.4 \pm 188.0$ \\
\hline$\Delta \mathrm{FEV}_{1} \%$ of initial $\mathrm{FEV}_{1}$ & $2.9 \pm 3.7$ & $3.4 \pm 4.4$ & $5.4 \pm 6.7$ & $6.0 \pm 8.8$ & $13.5 \pm 11.6$ \\
\hline $\begin{array}{l}\triangle \mathrm{FEV}_{1} \% \text { of predicted } \\
\mathrm{FEV}_{1}\end{array}$ & $2.8 \pm 3.6$ & $3.1 \pm 3.9$ & $4.4 \pm 4.9$ & $4.0 \pm 6.1$ & $7.7 \pm 5.1$ \\
\hline
\end{tabular}

Data are presented as $n$, mean \pm SD or $n(\%)$. Complete data were obtained in 2625 (99\%) for smoking history, 160 (84\%) for asthma severity. ACO: asthma-COPD overlap; BMI: body mass index; ICS: inhaled corticosteroid; $\mathrm{BD}$ : bronchodilator; $\mathrm{FEV}_{1}$ : forced expiratory volume in $1 \mathrm{~s}$; FVC: forced vital capacity; BDR: bronchodilator reversibility. \#: reference sample criteria: never-asthma, never-smoker, no respiratory symptoms in the past 12 months. 
symptomatic subsample of the TAHS cohort, consisting of participants who self-reported one or more respiratory symptoms in the past 12 months (wheeze, shortness of breath or chest tightness). Details of the survey questionnaire used to define the symptomatic sample are provided in supplementary methods E2.

Two sensitivity analyses were performed. In the first sensitivity analysis, we excluded all participants who were on regular ICS to assess whether treatment status influenced on diagnostic utility. In the second sensitivity analysis, we used an amended definition of current asthma (based on symptoms, healthcare or medication utilisation in the past 12 months, rather than 1 month) more commonly used in epidemiological studies (see supplementary methods E3 for further details). All analyses were performed using STATA (version 15.1; Stata Corporation 2019, College Station, TX, USA).

\section{Results}

\section{Participant characteristics}

Of the 3609 participants in the 2012 TAHS follow-up, 2646 (73\%) completed both pre- and post-BD spirometry. Of these, 2367 (89\%) had no airways disease, 148 (6\%) met the criteria for current asthma with self-reported doctor-diagnosed asthma, 88 (3\%) met the criteria for spirometrically defined COPD and $43(2 \%)$ met the criteria for ACO. The basic characteristics of these groups are presented in table 1 (general sample) and supplementary table E5 (symptomatic sample).

The mean $\pm \mathrm{SD} \Delta \mathrm{FEV}_{1}$ in the reference sample was $91.9 \pm 121.0 \mathrm{~mL}$, the $\Delta \mathrm{FEV}_{1}$ initial was $2.9 \pm 3.7 \%$ and the $\Delta \mathrm{FEV}_{1}$ pred was $2.8 \pm 3.6 \%$. The corresponding ULN values were $280 \mathrm{~mL}, 9.3 \%$ and $8.8 \%$, respectively. Compared to the reference sample, BDR was significantly higher in adults with each form of obstructive airways disease (supplementary table E1; $<<0.002$ for all comparisons). The magnitude of BDR was significantly higher in adults with ACO compared to both current asthma (mean difference (MD) $+111.7 \mathrm{~mL} ; \mathrm{p}<0.001)$ and COPD $(\mathrm{MD}+129.9 \mathrm{~mL} ; \mathrm{p}<0.001)$, probably related to a lower baseline $\mathrm{FEV}_{1}$ in the ACO group (65\% pred). In contrast, BDR was not significantly different between current asthma and COPD (MD -18.2 mL; $\mathrm{p}=0.44$ ), despite a much lower baseline $\mathrm{FEV}_{1}$ in adults with $\mathrm{COPD}$ (92\% versus $79 \%$ pred, respectively). Among adults with either current asthma or ACO, those with current ICS use had greater BDR compared to those who were untreated (supplementary table E2).

\section{Comparison of BDR measurements (ROC curves)}

Whereas all continuous BDR measurements performed similarly for current asthma, the areas under the ROC curve (AUC) for ACO was highest when BDR was expressed as $\triangle \mathrm{FEV}_{1}$ initial as compared to $\Delta \mathrm{FEV}_{1}$ or $\Delta \mathrm{FEV}_{1}$ pred (table 2 and figure 2). The corresponding AUC was 59\% (95\% CI 54-64\%) for current asthma and $87 \%$ (95\% CI 81-93\%) for ACO. Findings were similar when ROC curves were developed for the symptomatic sample (table 2 and figure 2).

\section{Diagnostic parameters of BDR cut-offs}

All cut-offs investigated had low sensitivities, but high specificities for both current asthma and ACO (table 3). Cut-offs were generally more sensitive for ACO (12-60\%) than for current asthma (5-20\%), but were highly specific for both conditions (92-99\%). The positive likelihood ratios ranged between 2.09 and 4.83 for current asthma, and between 5.40 and 16.05 for ACO. The negative likelihood ratios ranged between 0.87 and 0.96 for current asthma, and between 0.43 and 0.89 for ACO.

\begin{tabular}{|c|c|c|}
\hline & Asthma \% & $\mathrm{ACO} \%$ \\
\hline \multicolumn{3}{|l|}{ General sample (whole cohort) } \\
\hline$\Delta \mathrm{FEV}_{1} \mathrm{~mL}$ & $57(52-62)$ & $79(73-86)$ \\
\hline$\Delta \mathrm{FEV}_{1} \%$ of initial $\mathrm{FEV}_{1}$ & $59(54-64)$ & 87 (81-93) \\
\hline$\Delta \mathrm{FEV}_{1} \%$ of predicted $\mathrm{FEV}_{1}$ & $57(52-62)$ & $79(73-86)$ \\
\hline \multicolumn{3}{|l|}{ Symptomatic sample } \\
\hline$\Delta \mathrm{FEV}_{1} \mathrm{~mL}$ & $56(50-61)$ & $76(69-83)$ \\
\hline$\Delta \mathrm{FEV}_{1} \%$ of initial $\mathrm{FEV}_{1}$ & $56(50-61)$ & $84(78-90)$ \\
\hline$\Delta \mathrm{FEV}_{1} \%$ of predicted $\mathrm{FEV}_{1}$ & $55(50-61)$ & $77(69-84)$ \\
\hline
\end{tabular}



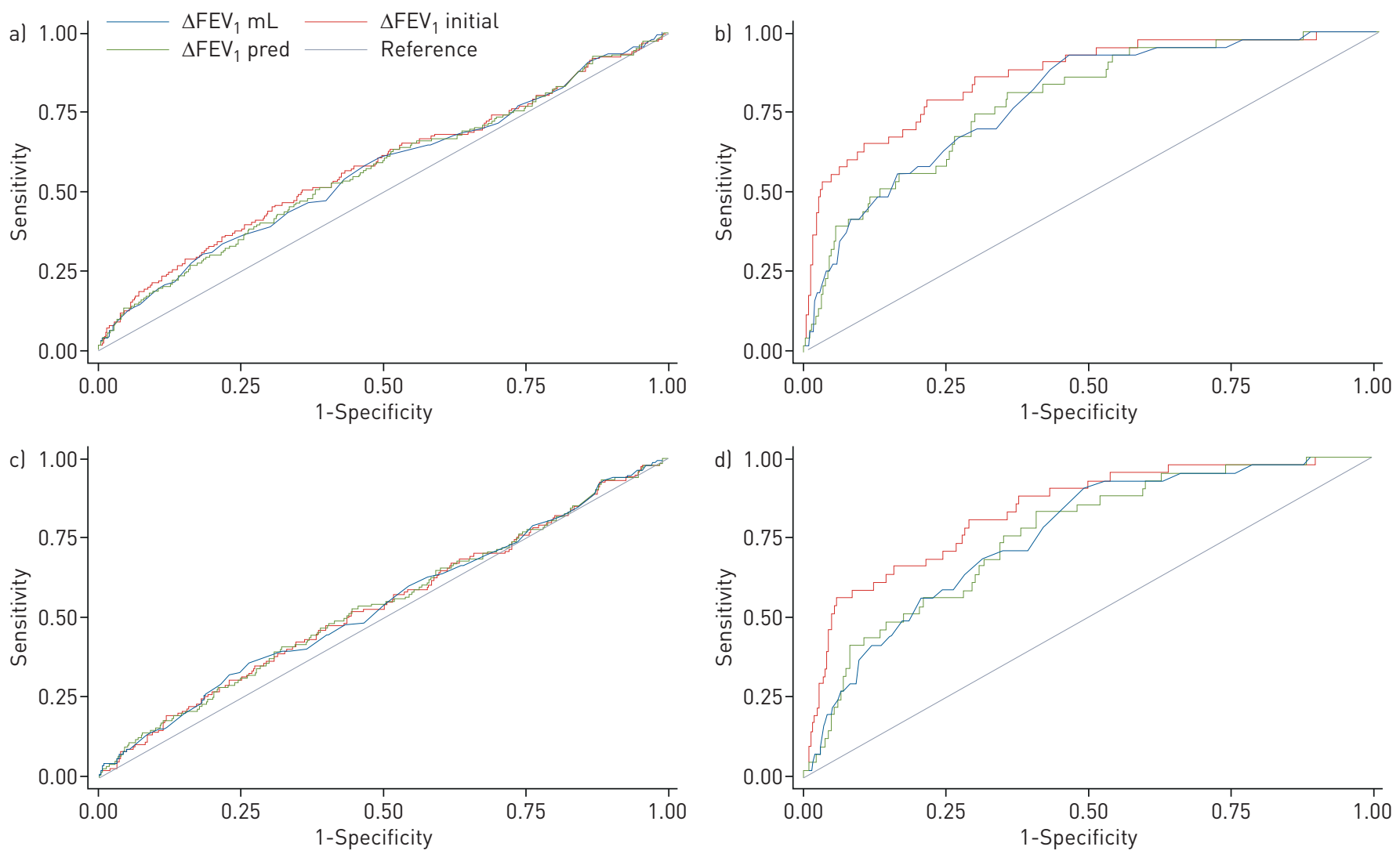

FIGURE 2 Receiver operator characteristic curves of the bronchodilator reversibility measures for a,c) current doctor-diagnosed asthma and $b, d)$ asthma-COPD overlap in the a,b) general and c,d) symptomatic samples. FEV ${ }_{1}$ : forced expiratory volume in $1 \mathrm{~s}$.

Using the diagnostic odds ratio as a single indicator of diagnostic performance, the best cut-off for current asthma was $\triangle \mathrm{FEV}_{1} 15 \%$ of initial $+400 \mathrm{~mL}$. However, even this cut-off performed relatively poorly, with a positive likelihood ratio of 4.83, negative likelihood ratio of 0.96 and diagnostic odds ratio of 5.02 (95\% CI 2.13-11.85). In contrast, the optimal cut-off for ACO was $\Delta \mathrm{FEV}_{1} 12 \%$ of initial $+200 \mathrm{~mL}$, which provided a positive likelihood ratio of 16.05, a negative likelihood ratio of 0.55 and diagnostic odds ratio of 29.14 (95\% CI 15.30-55.48).

Overall, the ATS/ERS cut-off $\left(\Delta \mathrm{FEV}_{1} 12 \%\right.$ of initial $\left.+200 \mathrm{~mL}\right)$ was assessed as providing the best balance between positive and negative likelihood ratios, corresponding to sensitivities and specificities of $9 \%$ and 97\%, respectively, for current asthma (positive likelihood ratio 3.26, negative likelihood ratio 0.93), and $47 \%$ and 97\%, respectively, for ACO (positive likelihood ratio 16.05, negative likelihood ratio 0.55). Compared to the general sample, cut-offs in the symptomatic sample were marginally less specific, but had similar sensitivities (table 4); positive likelihood ratios were slightly lower, whereas negative likelihood ratios were largely unchanged.

\section{Sensitivity analyses}

The findings of the sensitivity analyses are presented in the supplementary material. The AUC and diagnostic parameters of the BDR measurements and cut-offs were largely unchanged when participants on regular ICS were excluded from the analyses (supplementary tables E6-E8) or when a 12-month (instead of 1-month) definition of current asthma was used (supplementary tables E9-E12).

\section{Discussion}

Using data from a prospective Australian community-based cohort followed from age 7 to 53 years, we compared the discriminatory accuracy of common BDR measurements and cut-offs for adult asthma. Across a range of cut-off points, $\triangle \mathrm{FEV}_{1}, \Delta \mathrm{FEV}_{1}$ initial and $\Delta \mathrm{FEV}_{1}$ pred performed similarly for current asthma, whereas $\triangle \mathrm{FEV}_{1}$ initial performed better than $\triangle \mathrm{FEV}_{1}$ and $\triangle \mathrm{FEV}_{1}$ pred for ACO. The discriminatory accuracy of these measures were better for ACO compared to current asthma. All cut-offs examined in this study had low sensitivities, but high specificities for both current asthma and ACO, missing $\geqslant 80 \%$ of those with current asthma and approximately half of those with ACO. 
TABLE 3 General sample: diagnostic parameters of bronchodilator reversibility cut-off points for current doctor-diagnosed asthma and asthma-COPD overlap (ACO)

\begin{tabular}{|c|c|c|c|c|c|c|}
\hline $\begin{array}{c}\text { Sensitivity \% } \\
\text { (95\% CI) }\end{array}$ & $\begin{array}{c}\text { Specificity \% } \\
(95 \% \mathrm{CI})\end{array}$ & $\begin{array}{c}\text { Positive } \\
\text { predictive } \\
\text { value } \% \\
\text { (95\% CI) }\end{array}$ & $\begin{array}{c}\text { Negative } \\
\text { predictive } \\
\text { value } \% \\
(95 \% \mathrm{Cl})\end{array}$ & $\begin{array}{l}\text { Positive } \\
\text { likelihood } \\
\text { ratio } \\
(95 \% \mathrm{CI})\end{array}$ & $\begin{array}{c}\text { Negative } \\
\text { likelihood } \\
\text { ratio } \\
(95 \% \mathrm{Cl})\end{array}$ & $\begin{array}{l}\text { Diagnostic } \\
\text { OR }(95 \% \mathrm{CI})\end{array}$ \\
\hline
\end{tabular}

\begin{tabular}{|c|c|c|c|c|c|c|c|}
\hline \multicolumn{8}{|l|}{ Asthma } \\
\hline$\Delta \mathrm{FEV}_{1}(\mathrm{~mL}) \mathrm{ULN}^{\#}$ & $16(11-23)$ & 92 (91-93) & $11(7-16)$ & 95 (94-96) & $\begin{array}{c}2.09 \\
(1.42-3.09)\end{array}$ & $\begin{array}{c}0.91 \\
(0.85-0.98)\end{array}$ & $\begin{array}{c}2.30 \\
(1.45-3.65)\end{array}$ \\
\hline $\begin{array}{l}\triangle \mathrm{FEV}_{1} \% \text { of initial } \\
\mathrm{FEV}_{1} \mathrm{ULN}^{\text {? }}\end{array}$ & 20 (14-27) & 92 (91-93) & 13 (9-19) & $95(94-96)$ & $\begin{array}{c}2.58 \\
(1.81-3.68)\end{array}$ & $\begin{array}{c}0.87 \\
(0.80-0.94)\end{array}$ & $\begin{array}{c}2.97 \\
(1.93-4.57)\end{array}$ \\
\hline $\begin{array}{l}\Delta \mathrm{FEV}_{1} \% \text { of } \\
\text { predicted } \mathrm{FEV}_{1} \\
\mathrm{ULN}^{+}\end{array}$ & $15(10-21)$ & 94 (93-95) & $13(8-19)$ & 95 (94-96) & $\begin{array}{c}2.40 \\
(1.58-3.63)\end{array}$ & $\begin{array}{c}0.91 \\
(0.85-0.97)\end{array}$ & $\begin{array}{c}2.64 \\
(1.63-4.27)\end{array}$ \\
\hline $\begin{array}{l}\Delta \mathrm{FEV}_{1} 15 \% \text { of } \\
\quad \text { initial }+400 \mathrm{~mL}\end{array}$ & $5(2-9)$ & 99 (99-99) & $23(10-41)$ & 95 (94-95) & $\begin{array}{c}4.83 \\
(2.12-11.02)\end{array}$ & $\begin{array}{c}0.96 \\
(0.93-1.00)\end{array}$ & $\begin{array}{c}5.02 \\
(2.13-11.85)\end{array}$ \\
\hline \multicolumn{8}{|l|}{ ACO } \\
\hline$\Delta \mathrm{FEV}_{1}(\mathrm{~mL}) \mathrm{ULN}^{\#}$ & $42(28-57)$ & $92(91-93)$ & $9(5-13)$ & 99 (98-99) & $\begin{array}{c}5.40 \\
(3.70-7.88)\end{array}$ & $\begin{array}{c}0.63 \\
(0.49-0.81)\end{array}$ & $\begin{array}{c}8.56 \\
(4.59-15.98)\end{array}$ \\
\hline $\begin{array}{c}\Delta \mathrm{FEV}_{1} \% \text { of initial } \\
\mathrm{FEV}_{1} \mathrm{ULN}^{\text {? }}\end{array}$ & $60(46-74)$ & 92 (91-93) & $12(8-17)$ & 99 (99-100) & $\begin{array}{c}7.96 \\
(6.03-10.52)\end{array}$ & $\begin{array}{c}0.43 \\
(0.30-0.62)\end{array}$ & $\begin{array}{c}18.62 \\
(9.92-34.93)\end{array}$ \\
\hline $\begin{array}{l}\Delta \mathrm{FEV}_{1} 12 \% \text { of } \\
\quad \text { initial }+200 \mathrm{~mL}\end{array}$ & $47(33-61)$ & 97 (96-98) & $22(14-32)$ & 99 (99-99) & $\begin{array}{c}16.05 \\
(10.82-23.80)\end{array}$ & $\begin{array}{c}0.55 \\
(0.42-0.73)\end{array}$ & $\begin{array}{c}29.14 \\
(15.30-55.48)\end{array}$ \\
\hline $\begin{array}{l}\Delta \mathrm{FEV}_{1} 15 \% \text { of } \\
\quad \text { initial }+400 \mathrm{~mL}\end{array}$ & $12(5-24)$ & 99 (99-99) & $17(6-36)$ & 98 (98-99) & $\begin{array}{c}11.87 \\
(4.75-29.64)\end{array}$ & $\begin{array}{c}0.89 \\
(0.80-1.00)\end{array}$ & $\begin{array}{c}13.30 \\
(4.82-36.72)\end{array}$ \\
\hline
\end{tabular}

The ULN of BDR in "healthy" nonsmokers in this middle-aged Australian cohort $\left(\Delta \mathrm{FEV}_{1} 280 \mathrm{~mL}\right.$, $\triangle \mathrm{FEV}_{1}$ initial $9.3 \%, \Delta \mathrm{FEV}_{1}$ pred $\left.8.8 \%\right)$ was consistent with previous reports [7]. In a recent review of seven population-based cohorts, ULN estimates ranged between 240 and $320 \mathrm{~mL}$ for $\Delta \mathrm{FEV}_{1}$, between $5.9 \%$ and $13 \%$ for $\Delta \mathrm{FEV}_{1}$ initial, and between $8.7 \%$ and $11.6 \%$ for $\Delta \mathrm{FEV}_{1}$ pred $[8,18-23]$. Consistent with a recent analysis of three European cohorts [6], we found that BDR distributions were similar in adults with current asthma and those with COPD, but significantly higher in ACO compared to either current asthma or COPD. While there is ongoing debate around the usefulness of BDR in distinguishing obstructive airways diseases $[24,25]$, our findings indicate that BDR has some phenotypic value in delineating ACO (current asthma in those with fixed airflow obstruction) from common COPD.

A long-standing issue surrounding the clinical application of BDR has been the lack of agreement on how it should be expressed $[4,16,26] . \Delta \mathrm{FEV}_{1}$ and $\Delta \mathrm{FEV}_{1}$ initial are most commonly used; however, cut-offs based on these measures tend to be biased by age, sex and other factors [11]. While the impact of these factors has been argued to have minimal clinical impact by some authors [27], others have recommended the use of age-specific BDR cut-offs [11] or alternative measurements with theoretically less susceptibility to bias such as $\Delta \mathrm{FEV}_{1}$ pred $[11,21]$, change in $\mathrm{FEV}_{1} \mathrm{z}$-score $\left(\Delta \mathrm{zFEV}_{1}\right)$ [21], or change in volume-based parameters such as $\triangle \mathrm{FVC}$. The latter two approaches are not widely used, although there is some evidence that $\triangle \mathrm{FVC}$ may be more clinically relevant in severe airways obstruction [21]. Our study was inherently standardised by age by nature of recruitment and found that across a range of thresholds, $\Delta \mathrm{FEV}_{1}$ initial provided a better diagnostic utility compared to $\triangle \mathrm{FEV}_{1}$ and $\triangle \mathrm{FEV}_{1}$ pred, despite these theoretical advantages, and accounted for low baseline $\mathrm{FEV}_{1}$, especially relevant to those in the ACO subgroup.

ATS guidelines first recommended a cut-off for the diagnosis of asthma of $\Delta \mathrm{FEV}_{1} \geqslant 12 \%$ from baseline and $\geqslant 200 \mathrm{~mL}$ in 1991 [26], with these thresholds based on studies of small numbers of patients with obstructive airways defects [27-29]. In the years since, few studies have evaluated the sensitivities and specificities of common cut-offs for obstructive airways diseases [7]. An obstacle is that there is no single "gold standard" test for current asthma, and its diagnosis often requires a degree of clinical judgement. In an Australian population-based study, the sensitivities of BDR for current doctor-diagnosed asthma ranged 
TABLE 4 Symptomatic sample: diagnostic parameters of bronchodilator reversibility cut-off points for current doctor-diagnosed asthma and asthma-COPD overlap (ACO)

$\begin{array}{ccccccc}\begin{array}{c}\text { Sensitivity } \% \\ (95 \% \mathrm{CI})\end{array} & \begin{array}{c}\text { Specificity } \% \\ (95 \% \mathrm{Cl})\end{array} & \begin{array}{c}\text { Positive } \\ \text { predictive }\end{array} & \begin{array}{c}\text { Negative } \\ \text { predictive }\end{array} & \begin{array}{c}\text { Positive } \\ \text { likelihood }\end{array} & \begin{array}{c}\text { Negative } \\ \text { likelihood }\end{array} & \begin{array}{c}\text { Diagnostic } \\ \text { OR }(95 \% \mathrm{Cl})\end{array} \\ & & \text { value } \% & \text { ratio } & \text { ratio } & \\ & & (95 \% \mathrm{Cl}) & (95 \% \mathrm{Cl}) & (95 \% \mathrm{CI}) & (95 \% \mathrm{CI}) & \end{array}$

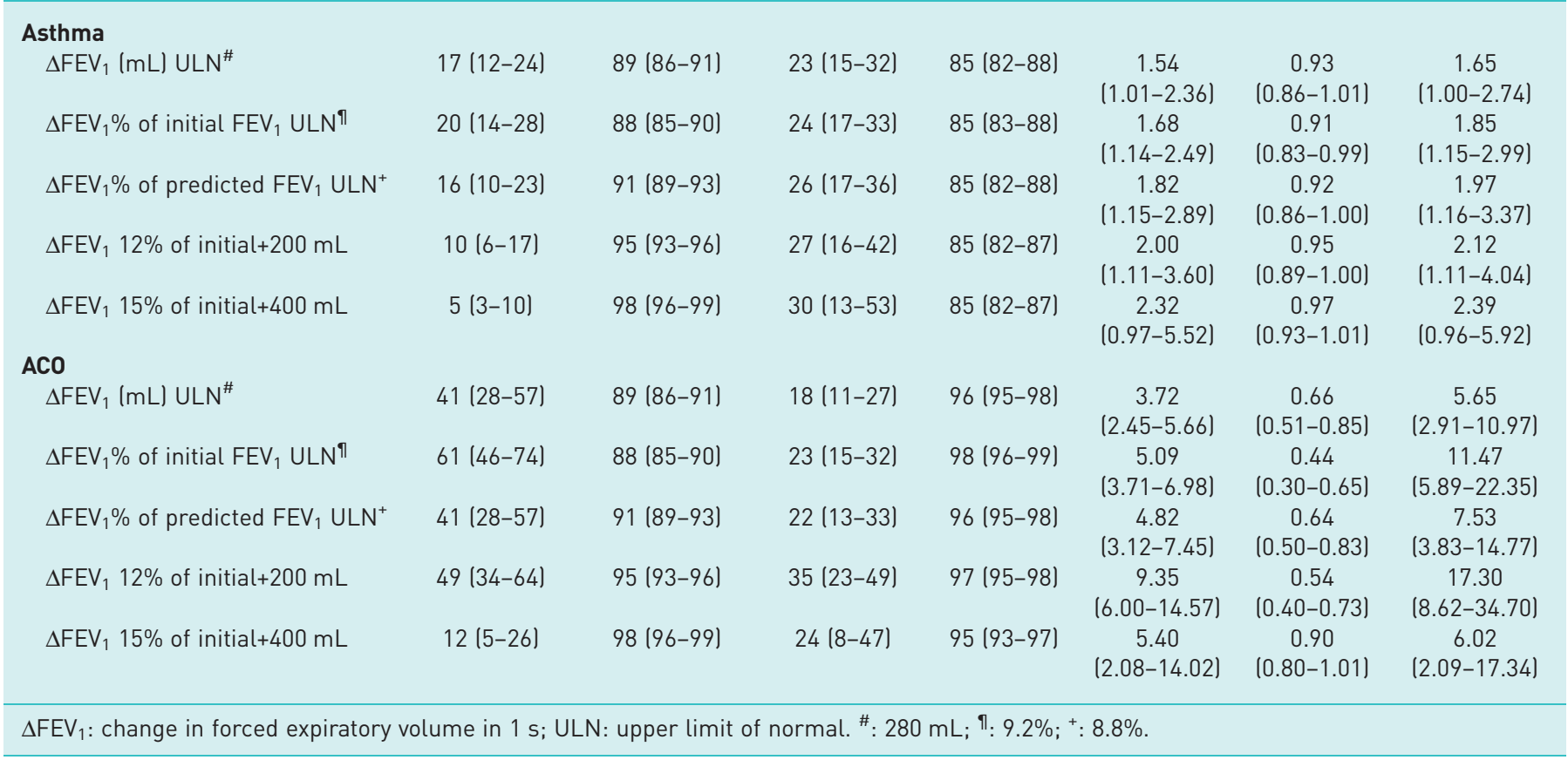

between $7 \%$ and $18 \%$ depending on the cut-off $\left(\Delta \mathrm{FEV}_{1} \geqslant 400 \mathrm{~mL}\right.$ versus $\Delta \mathrm{FEV}_{1}$ pred $\left.\geqslant 9 \%\right)$ [11]. In a study of 190 participants with asthma-like symptoms, a cut-off of $\Delta \mathrm{FEV}_{1}$ initial $>12 \%$ provided a sensitivity of $13 \%$ and specificity of $93 \%$ compared to clinical opinions from a panel of three respiratory physicians [30]. While the first study was performed in steroid-naïve patients, approximately half of the participants in the second study were on ICS treatment at the time of assessment. As observed in our study, participants on ICS had higher BDR responses than those who were untreated, consistent with these participants being more likely to have greater disease activity and/or severity [30].

All cut-offs examined in our study demonstrated low sensitivities, but high specificities for both current asthma and ACO. These findings imply that a positive test could assist with ruling in a diagnosis of asthma, whereas a negative test was unhelpful. Of note, positive and negative likelihood ratios provide a more robust measure of test performance with respect to pre- and post-test probabilities. A high positive likelihood ratio $(>5)$ implies that a positive test provides a clinically meaningful increase in the post-test probability of the disease [31]. In contrast, a low negative likelihood ratio $(<0.2)$ implies that a negative test would provide a clinically meaningful decrease in the post-test probability of the disease [31]. Most positive and negative likelihood ratios for adult asthma fell within the clinically unhelpful range of $0.2-5$, indicating the test was of limited diagnostic value. A notable exception was the relatively high positive likelihood ratios achieved for ACO, particularly using the ATS/ERS guideline cut-off. Consequently, our results reaffirm that BDR testing is more relevant in those with more severe disease and lower baseline lung function.

As expected, the sensitivities, specificities, positive and negative likelihood ratios of the BDR cut-offs were mostly unchanged between the analyses in the general and symptomatic samples. In contrast, the changes in positive and negative predictive values between the two analyses probably reflected differences in the prevalence of disease between the two populations.

\section{Strengths and limitations}

There are a number of strengths to our study. Firstly, our study has good external validity as our participants were derived from the general population. Secondly, due to the nature of recruitment, all participants were of similar age and we were able to assess the diagnostic parameters of BDR largely 
independently of age effects. Thirdly, we had access to prospective data collected from the first to sixth decades of life, which allowed us to more accurately determine our participants' lifetime asthma histories and delineate the healthy reference sample compared to previous studies. Finally, we examined the diagnostic parameters of different BDR measurements and cut-offs in both general and respiratory symptom populations using both clinical (1-month) and epidemiological (12-month) definitions.

There are several important limitations to the study. The narrow age-bracket of our participants potentially limits the generalisability of our results beyond a middle-aged adult population. Our gold-standard definition of asthma was based on self-reported features including a history of doctor-diagnosed asthma, which may have introduced misclassification (in cases of incorrect recall or incorrect diagnosis by the treating physician) and excluded those with undiagnosed asthma. Diagnoses of asthma in the community were likely to have been guided by existing ATS/ERS guidelines and thresholds. Finally, approximately half of our asthmatic participants were on ICS in the weeks prior to assessment. While these participants had higher BDR responses than those who were untreated, probably due to more severe disease, they may have had a reduced response compared to if they were ICS-naïve. Consequently, our results probably underestimate the sensitivity of BDR cut-offs in treatment-naïve adult asthma, despite findings being relatively unchanged in the sensitivity analysis which excluded ICS users. Therefore, future studies in patients with newly diagnosed, treatment-naïve patients are still required.

\section{Conclusion}

BDR remains a simple and inexpensive method of measuring expiratory airflow variability. Applying the thresholds examined in this study, a positive BDR test provides a clinically meaningful change in the post-test probability of asthma, whereas a negative test does not. In the presence of typical clinical features, a negative test therefore warrants further investigations. Overall, our findings identify important limitations of BDR testing, but support its use as an initial investigation in the work-up of suspected adult asthma and ACO, with an optimal threshold of $\geqslant 12 \%$ and $\geqslant 200 \mathrm{~mL}$ from baseline.

Acknowledgements: We acknowledge the TAHS study participants and previous investigators, Heather Gibson, Bryan Gandevia, Harold Silverstone and Norelle Lickiss. We thank Mark Jenkins, Lyle Gurrin, Graham Giles, John Hopper (Centre for Epidemiology and Biostatistics, Victoria), Alan James (Sir Charles Gairdner Hospital, Nedlands, Western Australia), Peter Frith (Flinders University, Adelaide), Richard Wood-Baker (Tasmanian School of Medicine, Tasmania) and Iain Feather (Gold Coast Hospital, Queensland), who are TAHS investigators but not coauthors of this manuscript, for their assistance with obtaining funds and data collection. We also acknowledge the study site coordinators and respiratory scientists who collected data in lung function laboratories in Tasmania, Victoria, Queensland and New South Wales, the research interviewers and data entry operators; and the organisational roles of Cathryn Wharton (Centre for Epidemiology and Biostatistics) and Desiree Mészáros (Tasmanian School of Medicine). Furthermore, we thank the late Stephen Morrison (University of Queensland) for his assistance with obtaining funds and data collection.

Ethics approval: This study was approved by separate human ethics review committees at all participating institutions, principally the University of Melbourne (040375) and the University of Tasmania (H0012710). Written informed consent was obtained from all participants. All data used in this study were de-identified.

Conflict of interest: D.J. Tan has nothing to disclose. C.J. Lodge has nothing to disclose. A.J. Lowe has nothing to disclose. D.S. Bui has nothing to disclose. G. Bowatte has nothing to disclose. D.P. Johns has nothing to disclose. G.S. Hamilton has nothing to disclose. P.S. Thomas reports having participated in advisory board meetings for GSK and AstraZeneca, unrelated to this work. M.J. Abramson reports investigator-initiated grants for unrelated research from Pfizer and Boehringer Ingelheim, personal fees for unrelated consultancy and assistance with conference attendance from Sanofi, and a speaker's fee from GSK, outside the submitted work. E.H. Walters has nothing to disclose. J.L. Perret reports a travel grant from Boehringer Ingelheim, outside the submitted work. S.C. Dharmage has nothing to disclose.

Support statement: This study was supported by the National Health and Medical Research Council (NHMRC) of Australia; the University of Melbourne, Clifford Craig Foundation; the Victorian, Queensland and Tasmanian Asthma Foundations; Royal Hobart Hospital; Helen MacPherson Smith Trust; and GlaxoSmithKline. The funding bodies had no direct role in the conduct of the study, the collection, management, statistical analysis and interpretation of the data, preparation or approval of the manuscript. D.J. Tan was funded by a NHMRC Postgraduate Scholarship and Royal Australian College of Physicians (RACP) Woolcock Scholarship. Funding information for this article has been deposited with the Crossref Funder Registry.

\section{References}

1 Global Initiative for Asthma (GINA). Global Strategy for Asthma Management and Prevention. 2019. Available from: http://ginasthma.org.

2 National Institute for Health and Care Excellence (NICE). Asthma: Diagnosis, Monitoring and Chronic Asthma Management. NICE guideline [NG80]. 2017. www.nice.org.uk/guidance/ng80 Date last updated: February 12, 2020.

3 Pavord ID, Beasley R, Agusti A, et al. After asthma: redefining airways diseases. Lancet 2018; 391: 350-400.

4 Brand PL, Quanjer PH, Postma DS, et al. Interpretation of bronchodilator response in patients with obstructive airways disease. The Dutch Chronic Non-Specific Lung Disease (CNSLD) Study Group. Thorax 1992; 47: 429-436. 
5 Aaron SD, Vandemheen KL, FitzGerald JM, et al. Reevaluation of diagnosis in adults with physician-diagnosed asthma. JAMA 2017; 317: 269-279.

6 Janson C, Malinovschi A, Amaral AFS, et al. Bronchodilator reversibility in asthma and COPD: findings from three large population studies. Eur Respir J 2019; 54: 1900561.

7 Tuomisto LE, Ilmarinen $\mathrm{P}$, Lehtimäki L, et al. Immediate bronchodilator response in $\mathrm{FEV}_{1}$ as a diagnostic criterion for adult asthma. Eur Respir J 2019; 53: 1800904.

8 Tan WC, Vollmer WM, Lamprecht B, et al. Worldwide patterns of bronchodilator responsiveness: results from the Burden of Obstructive Lung Disease study. Thorax 2012; 67: 718-726.

9 Pennock BE, Rogers RM, McCaffree DR. Changes in measured spirometric indices. What is significant? Chest 1981; 80: 97-99.

10 Sourk RL, Nugent KM. Bronchodilator testing: confidence intervals derived from placebo inhalations. Am Rev Respir Dis 1983; 128: 153-157.

11 Appleton SL, Adams RJ, Wilson DH, et al. Spirometric criteria for asthma: adding further evidence to the debate. J Allergy Clin Immunol 2005; 116: 976-982.

12 Matheson MC, Abramson MJ, Allen K, et al. Cohort profile: the Tasmanian Longitudinal Health Study (TAHS). Int J Epidemiol 2017; 46: 407-408i.

13 Gibson HB, Silverstone H, Gandevia B, et al. Respiratory disorders in seven-year-old children in Tasmania. Aims, methods and administration of the survey. Med J Aust 1969; 2: 201-205.

14 Miller MR, Hankinson J, Brusasco V, et al. Standardisation of spirometry. Eur Respir J 2005; 26: 319-338.

15 Quanjer PH, Stanojevic S, Cole TJ, et al. Multi-ethnic reference values for spirometry for the 3-95-yr age range: the global lung function 2012 equations. Eur Respir J 2012; 40: 1324-1343.

16 Pellegrino R, Viegi G, Brusasco V, et al. Interpretative strategies for lung function tests. Eur Respir J 2005; 26 : 948-968.

17 Glas AS, Lijmer JG, Prins MH, et al. The diagnostic odds ratio: a single indicator of test performance. J Clin Epidemiol 2003; 56: 1129-1135.

18 Lorber DB, Kaltenborn W, Burrows B. Responses to isoproterenol in a general population sample. Am Rev Respir Dis 1978; 118: 855-861.

19 Dales RE, Spitzer WO, Tousignant P, et al. Clinical interpretation of airway response to a bronchodilator. Epidemiologic considerations. Am Rev Respir Dis 1988; 138: 317-320.

20 Kainu A, Lindqvist A, Sarna S, et al. $\mathrm{FEV}_{1}$ response to bronchodilation in an adult urban population. Chest 2008 134: 387-393.

21 Quanjer PH, Ruppel GL, Langhammer A, et al. Bronchodilator response in FVC is larger and more relevant than in $\mathrm{FEV}_{1}$ in severe airflow obstruction. Chest 2017; 151: 1088-1098.

22 Torén K, Bake B, Olin AC, et al. Measures of bronchodilator response of $\mathrm{FEV}_{1}, \mathrm{FVC}$ and SVC in a Swedish general population sample aged 50-64 years, the SCAPIS Pilot Study. Int J Chron Obstruct Pulmon Dis 2017; 12 973-980.

23 Watanabe S, Renzetti AD Jr, Begin R, et al. Airway responsiveness to a bronchodilator aerosol. I. Normal human subjects. Am Rev Respir Dis 1974; 109: 530-537.

24 Chhabra SK. Acute bronchodilator response has limited value in differentiating bronchial asthma from COPD. J Asthma 2005; 42: 367-372.

25 Miravitlles M. Diagnosis of asthma-COPD overlap: the five commandments. Eur Respir J 2017; 49: 1700506.

26 Lung function testing: selection of reference values and interpretative strategies. American Thoracic Society. Am Rev Respir Dis 1991; 144: 1202-1218.

27 Eliasson O, Degraff AC Jr. The use of criteria for reversibility and obstruction to define patient groups for bronchodilator trials. Influence of clinical diagnosis, spirometric, and anthropometric variables. Am Rev Respir Dis 1985; 132: 858-864.

28 Criteria for the assessment of reversibility in airways obstruction. Report of the Committee on Emphysema American College of Chest Physicians. Chest 1974; 65: 552-553.

29 Pellegrino R, Rodarte JR, Brusasco V. Assessing the reversibility of airway obstruction. Chest 1998; 114: $1607-1612$.

30 Backer V, Sverrild A, Ulrik CS, et al. Diagnostic work-up in patients with possible asthma referred to a university hospital. Eur Clin Respir J 2015; 2: 27768.

31 McGee S. Simplifying likelihood ratios. J Gen Intern Med 2002; 17: 646-649. 